\title{
Sintering Fundamentals of Magnetite Alone and Blended with Hematite and Hematite/Goethite Ores
}

\author{
L. X. YANG \\ Newcastle Technology Centre, BHP Billiton Technology, PO Box 188, Wallsend 2287, Australia. \\ (Received on August 31, 2004; accepted on November 29, 2004)
}

\begin{abstract}
This work overviews the properties and sintering behaviour of Chinese magnetite concentrates, and interactions between magnetite concentrates and imported hematite, hematite/goethite ores in sintering. Sintering performance of several Chinese ore blends was also presented to provide greater understanding of the behaviour of imported hematite and hematite/goethite ores.

Chinese magnetite concentrates are generally more complex in chemistry and mineralogy and less reactive compared to hematite, Marra Mamba and goethite ores. Sinter beds formed from blends containing high level of magnetite concentrate are more deformable, and thus this could reduce their green bed permeability during charging and application of suction. SFCA formation in magnetite sintering occurs primarily in the cooling stage as magnetite oxidation is rather limited prior to the arrival of high temperature zone.

Porous hematite and Marra Mamba ores are easy to react and hence assist melt formation. Addition of porous hematite and Marra Mamba ores to magnetite concentrates improves granulation efficiency and sintering performance considerably.
\end{abstract}

KEY WORDS: magnetite concentrate; Marra Mamba; goethite; sintering; iron ore; magnetite oxidation; assimilation.

\section{Introduction}

Import of iron ores into China is significant and rising. Domestic ores for sintering in China are primarily magnetite concentrates. Many Chinese sinter plants use imported ores and domestic magnetite concentrates in their blends, and the level of imported ores varies significantly from mill to mill. Compared to the sintering of Chinese domestic ores, higher productivity, lower coke consumption and better sinter quality are often obtained by blending imported sinter fines with the domestic concentrates. The degree of the improvements was found to be dependent on the level of imported sinter fines in the blends, and on sintering operations. ${ }^{1)}$

Over the years, considerable fundamental research has been carried out to understand magnetite concentrate sintering $^{2,3)}$ and performance of hematite and hematite/goethite ores in the Chinese ore blend during sintering. ${ }^{4-9)}$ This paper discusses magnetite concentrate properties, its interactions with imported hematite and hematite/goethite ores during sintering, and sintering performance of several Chinese ore blends.

\section{Experimental}

Bench-scale sintering experiments such as assimilation and mineral formation during sintering were carried out using an infrared furnace, which closely simulated the sintering temperature profile seen from a sinter machine. ${ }^{10)}$
The analogue sinters made from the infrared furnace were subject to mineralogical analysis and the mineral composition was determined by the point-counting technique. ${ }^{3)}$ Pilot-scale sintering tests were carried out using a sinter pot of $320 \mathrm{~mm}$ diameter under the following conditions: ignition time $90 \mathrm{~s}$, ignition suction $8 \mathrm{kPa}$, sintering suction $12 \mathrm{kPa}$. Detailed technique has been given in a previous publication. $^{5)}$

\section{Properties and Sintering Behaviour of Chinese Magnetite Concentrates}

\subsection{Magnetite Concentrate Properties}

A number of Chinese magnetite concentrates were studied. Their chemical compositions (listed in Table 1) are complex and include many uncommon elements. Compared to BHP Billiton iron ores (e.g., $\mathrm{MAC}^{\mathrm{TM}}$ Fines: $\mathrm{Fe}=61.8 \%$, $\mathrm{SiO}_{2}=3.0 \%, \mathrm{Al}_{2} \mathrm{O}_{3}=1.9, \mathrm{CaO}=0.03 \%, \mathrm{MgO}=0.06 \%$ ), the concentrates are high in $\mathrm{CaO}$ and $\mathrm{MgO}$; and low in $\mathrm{Al}_{2} \mathrm{O}_{3} / \mathrm{SiO}_{2}$ ratio.

Table 2 gives the mineralogy for the above magnetite concentrates. Magnetite is the main iron oxide and hematite is also present. Ores E1 and E2 contain siderite. The gangue minerals are complex, and predominantly silicates and carbonates. Ore B also contains many uncommon minerals.

Figure 1 presents size distribution of the magnetite concentrates, indicating that most of the concentrates are almost $100 \%-0.5 \mathrm{~mm}$. On their own they are too fine for 
Table 1. Chemical composition of Chinese magnetite concentrates.

\begin{tabular}{cccccccccccccc}
\hline Ores & $\mathrm{Fe}$ & $\mathrm{FeO}$ & $\mathrm{SiO}_{2}$ & $\mathrm{Al}_{2} \mathrm{O}_{3}$ & $\mathrm{CaO}$ & $\mathrm{MgO}$ & $\mathrm{Mn}$ & $\mathrm{Zn}$ & $\mathrm{TiO}_{2}$ & $\mathrm{~K}_{2} \mathrm{O}$ & $\mathrm{S}$ & $\mathrm{P}$ & $\mathrm{LOI}$ \\
\hline $\mathrm{A}$ & 64.4 & 24.2 & 5.3 & 0.65 & 2.0 & 1.5 & 0.10 & 0.005 & 0.10 & 0.11 & 0.14 & 0.011 & -1.7 \\
\hline $\mathrm{B}^{*}$ & 59.1 & 17.7 & 5.1 & 0.34 & 2.9 & 1.0 & 1.0 & 0.035 & 0.28 & 0.18 & 0.99 & 0.110 & -0.5 \\
\hline $\mathrm{C}$ & 66.5 & 26.0 & 5.5 & 0.29 & 0.4 & 0.3 & 0.04 & 0.001 & 1.50 & 0.014 & 0.14 & 0.017 & -2.4 \\
\hline $\mathrm{D}$ & 55.8 & 25.0 & 5.2 & 0.91 & 0.3 & 0.4 & 0.07 & 0.001 & 0.12 & 0.026 & 0.06 & 0.16 & -12.6 \\
\hline $\mathrm{E} 1$ & 43.3 & 19.3 & 13.5 & 2.60 & 5.4 & 3.3 & 0.13 & 0.020 & 0.19 & 0.58 & 0.50 & 0.078 & 10.4 \\
\hline $\mathrm{E} 2$ & 64.4 & 25.1 & 3.1 & 0.88 & 1.0 & 1.5 & 0.13 & 0.015 & 0.11 & 0.18 & 0.42 & 0.015 & - \\
\hline $\mathrm{F}$ & 64.5 & 24.0 & 5.8 & 0.18 & 0.6 & 1.9 & 0.26 & 0.033 & 0.17 & 0.034 & 0.058 & 0.007 & -1.3 \\
\hline \multicolumn{8}{c}{ Concentrate B also contains $0.43 \% \mathrm{BaO}$ and } & $0.76 \%$ & $\mathrm{~F}$. & & & & \\
& LOI: loss on ignition.
\end{tabular}

Table 2. Mineral composition of some Chinese magnetite concentrates.

\begin{tabular}{lccccccc}
\hline Ores & $\mathrm{A}$ & $\mathrm{B}$ & $\mathrm{C}$ & $\mathrm{D}$ & $\mathrm{E} 1$ & $\mathrm{E} 2$ & $\mathrm{~F}$ \\
\hline Magnetite & 80.8 & 50.4 & 86.6 & 89.6 & 14.2 & 67.8 & 81.4 \\
\hline Hematite & 2.8 & 24.6 & 1.4 & 0.6 & 18.6 & 12.8 & 0.8 \\
\hline Goethite & 0.4 & 0.4 & - & - & & & 2.4 \\
\hline Quartz & 4.8 & 4.0 & 9.8 & 6.8 & 16.2 & 2.4 & 9.0 \\
\hline Pyroxene & 4.8 & 3.4 & 1.8 & 2.8 & 8.0 & 0.8 & 2.4 \\
\hline Pyrite & 0.2 & 0.8 & 0.2 & trace & 0.8 & 0.2 & \\
\hline Pyrrhotite & & 4.0 & & & 0.2 & 0.6 & trace \\
\hline Biotite & 3.0 & 2.0 & 0.2 & trace & 8.2 & 3.2 & 0.4 \\
\hline Carbonates & 1.2 & 3.0 & & 0.2 & 31.8 & 9.8 & 1.0 \\
\hline Fluorite & & 4.4 & & & & & \\
\hline Serpentine & & & & & & & \\
\hline Chalcopyrite & & & & & & & \\
\hline Others & 2.0 & 3.0 & & & & & \\
\hline
\end{tabular}

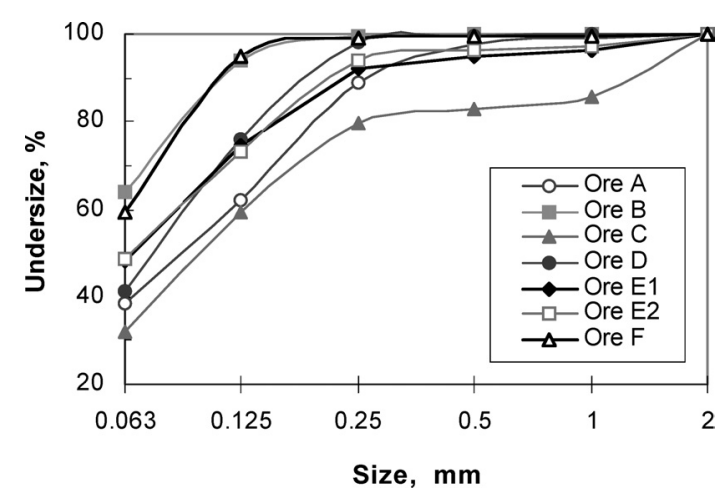

Fig. 1. Size distribution of the magnetite concentrates.

good sintering performance, unless granulation enhancement (e.g., mini-pellet sintering) is adopted.

\subsection{Performance of Magnetite Concentrates in Wet and Dry Zones of a Sintering Bed}

Performance of magnetite concentrate in wet and dry zones of a sinter bed was studied through measuring sinter "bed strength" using a technique developed in an earlier study. ${ }^{11)}$ Productivity is dependent on bed permeability, while permeability is a function of bed void, according to the equation below. ${ }^{12)}$

$$
\frac{\Delta p}{l}=\frac{150 \eta V_{0}\left(1-\varepsilon^{2}\right)}{\Phi^{2} d_{\mathrm{p}}^{2} \varepsilon^{2}}+\frac{1.75 \rho V_{0}^{2}(1-\varepsilon)}{\Phi d_{\mathrm{p}} \varepsilon^{3}}
$$

where $d_{\mathrm{p}}$ is the particle diameter, $l$ the bed height, $\Delta p$ the pressure drop through the bed, $V_{0}$ the superficial gas velocity, $\varepsilon$ the void fraction, $\eta$ the gas viscosity, $\rho$ the gas density, and $\Phi$ the shape factor.

Under given conditions, airflow increases if there is an increase in $\varepsilon$. In other words, changes in bed void $\varepsilon$ will

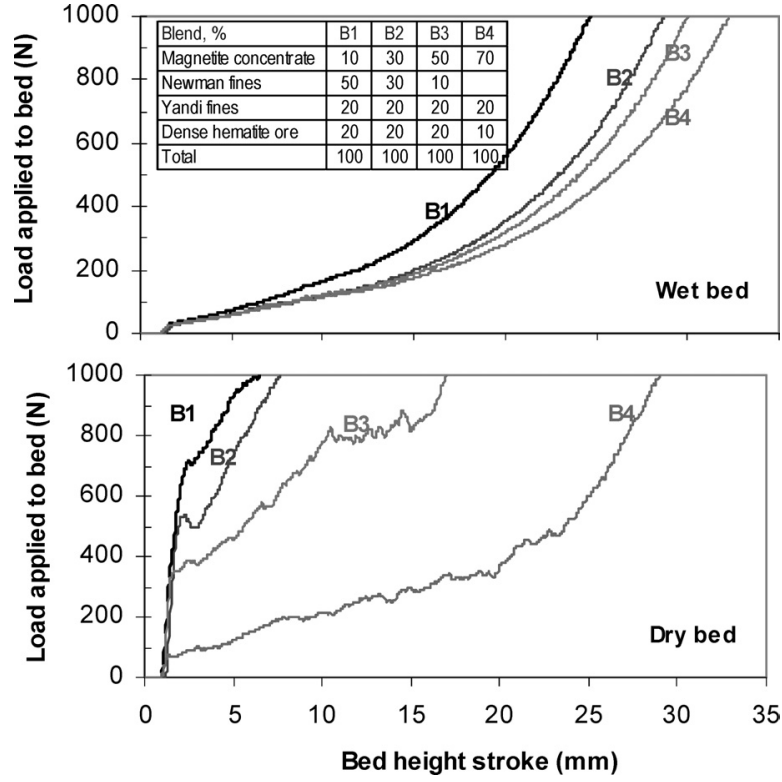

Fig. 2. Strength of wet and dry beds at various levels of magnetite concentrate (tests duplicated for each blend)

change airflow rate through the bed, i.e., permeability. If "bed strength" is defined as the resistance to deformation when a force is applied, bed strength can be determined by the reductions in bed height under increasing load. Obviously, the stronger the bed, the smaller the reductions in bed height. In this work, wet bed refers to a bed formed from green granulated sinter mix, while dry bed was obtained by flowing hot air through the wet bed until the relative humidity of the air from the system exit reached $40 \%$ at $40^{\circ} \mathrm{C}$.

Sinter mix consisting of the blended ore (seen in Fig. 2), $40 \%$ (ore basis) return fines, $15 \%$ (ore basis) limestone and $7 \%$ (ore basis) coke breeze was granulated at $6.5 \%$ moisture. The mix moisture was kept at constant $(6.5 \% \pm 0.2)$ for all the blends. Sinter bed strength for the four blends is presented in Fig. 2. It shows that when porous hematite ore (Newman fines) replaces magnetite concentrate in the blends, both wet and dry beds are stronger, i.e., bed height stroke is less for the same load applied to the bed, implying a stronger bed and probably improved bed permeability. At high levels of magnetite concentrate, the granules are more deformable and beds formed from such granules are more compressible. Thus, sinter beds containing high levels of magnetite concentrate generally show large shrinkage when suction is applied, resulting in a loss of their green bed permeability.

Figure 2 also indicates that dry bed is stronger than wet bed for the same blend, but the difference in bed strength 


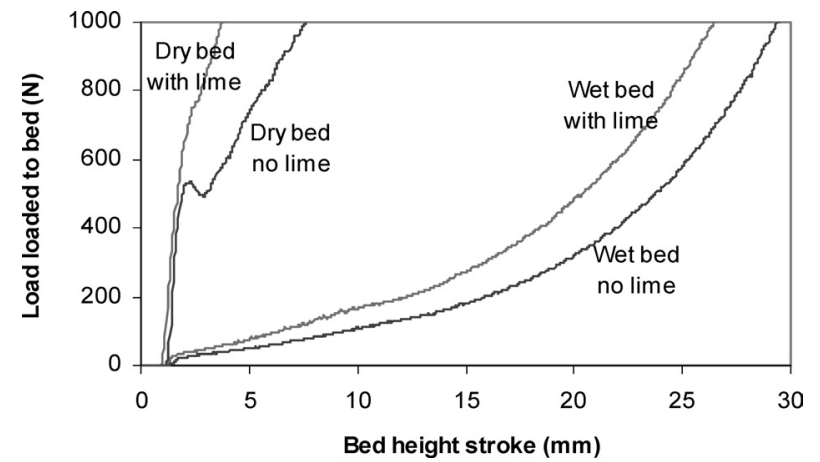

Fig. 3. Burnt lime effect on bed strength for Blend 2 (tests duplicated).

gets smaller with increasing magnetite concentrate in blends. For Blend 4 containing $70 \%$ magnetite concentrate, the dry bed strength is comparable to the wet bed, suggesting the bed is very weak at high levels of magnetite concentrate even after it is dried. Bed voidage will reduce significantly when a force (suction in the case of sintering) is applied to such beds. This is the reason why beds with high magnetite concentrates are weaker, making more difficult for air to pass through and therefore lower productivity.

In practice therefore, efforts are made to improve the bed strength by increasing coarse fines in blends and introducing additives such as burnt lime. Figure 3 shows that burnt lime improves strength of both wet and dry sinter beds for Blend 2 containing 30\% magnetite concentrate (blend composition given in Fig. 2).

\subsection{Magnetite Oxidation during Sintering}

Magnetite oxidation may be expressed by

$$
\mathrm{Fe}_{3} \mathrm{O}_{4}+\frac{1}{4} \mathrm{O}_{2}=\frac{3}{2} \mathrm{Fe}_{2} \mathrm{O}_{3} \quad \Delta H_{298}^{\circ}=-27400 \mathrm{cal}
$$

Obviously, the oxidation of magnetite is an exothermic reaction. The heat generated is roughly equivalent to that of 0.29 mol carbon being combusted to $\mathrm{CO}_{2}\left(\mathrm{C}+\mathrm{O}_{2}=\mathrm{CO}_{2}\right.$, $\left.\Delta H_{298}^{\circ}=-94490 \mathrm{cal}\right)$ when complete oxidation is achieved. If a coke breeze contains 85 mass \% carbon, every mole of magnetite $(232 \mathrm{~g})$ is equivalent to approximately $4 \mathrm{~g}$ coke. Thus, there is a great potential to reduce coke, provided the oxidation occurs.

\subsubsection{Factors Influencing Magnetite Oxidation in Sinter- ing}

Ore C (listed in Table 1) was chosen for extensive oxidation study since this ore contains mainly magnetite and simple gangue minerals. DTA/TG analyses of Ore C in air showed that magnetite oxidation started at approximately $200^{\circ} \mathrm{C}$ and completed at about $1100^{\circ} \mathrm{C}$. Oxidation studies were then carried out under conditions simulating sintering temperature profile using the infrared furnace. The results are presented in Fig. 4, where "Oxidation Degree" is defined as the fraction of hematite over the sum of magnetite and hematite. At a given temperature, oxidation degree increases significantly with the increasing residence time from 15 to $60 \mathrm{~s}$. However, oxidation degree is very low at the residence time of $15 \mathrm{~s}$, implying that the time period

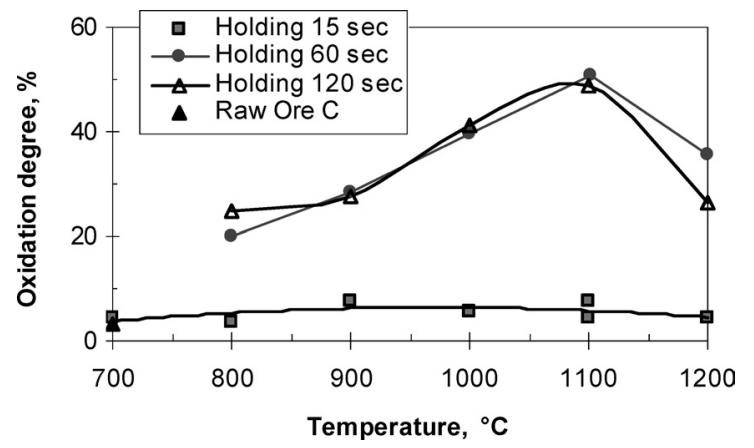

Fig. 4. Dependence of oxidation degree on residence time in static air.

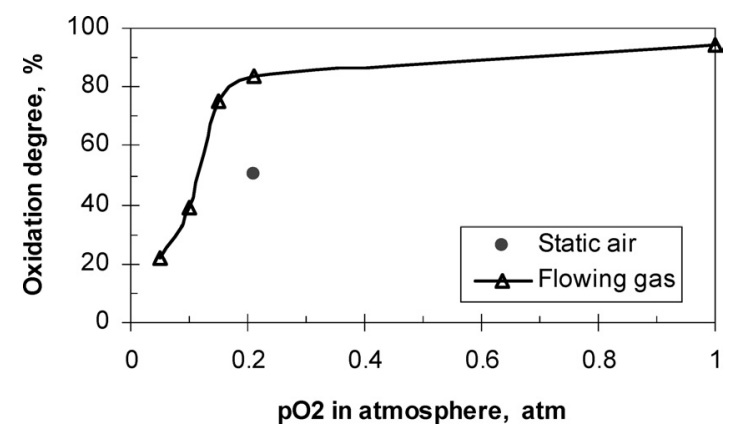

Fig. 5. Oxidation degree as function of oxygen partial pressure at $1100^{\circ} \mathrm{C}$ for ore $\mathrm{C}$.

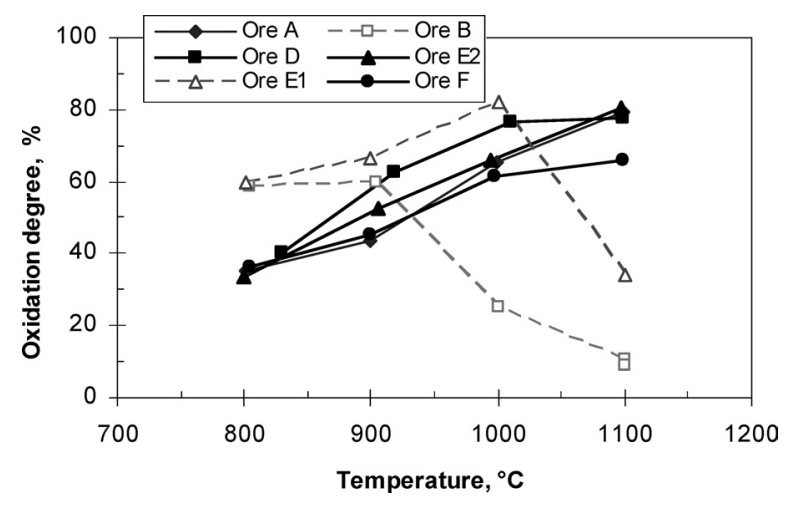

Fig. 6. Oxidation behaviour of various magnetite ores in flowing air at $60 \mathrm{~s}$ residence time.

that an ore particle exposed to air is very important for oxidation.

Figure 5 presents the relationship between oxidation degree and oxygen partial pressure at $1100^{\circ} \mathrm{C}$ and $60 \mathrm{~s}$ residence time for ore $\mathrm{C}$, showing that oxidation is a strong function of oxygen partial pressure, particularly at the oxygen partial pressures below air. Figure 5 also indicates that the oxidation in flowing air is significantly higher than that in static air.

Several magnetite concentrates were oxidised at varying temperatures and $60 \mathrm{~s}$ residence time. The results are compared in Fig. 6. Similar oxidation behaviour to ore $\mathrm{C}$ is exhibited by ores A, D, E2 and F while ore B is different, showing a sharp drop in hematite content above $900^{\circ} \mathrm{C}$. Ore E1 behaves rather differently to ore E2 although they are from the same steelworks and contain the same type of gangue minerals, i.e., a substantial drop in oxidation degree above $1000^{\circ} \mathrm{C}$ for ore $\mathrm{E} 1$. The difference in oxidation be- 
haviour for different ores may be attributed to ore size, the structure of magnetite itself and gangue mineral level and type in the ores.

Up to this stage, a bed formed from loose magnetite concentrate was used for oxidation studies. It was observed that samples became lumpy after being oxidised at high temperatures, indicating that sintering and inter-particle coalescence (or agglomeration) occurred during oxidation. There was also evidence of melt formation, particularly for the easy-fusing ore (ore B) and the ore containing high level of gangue minerals (ore E1). Figure 7 shows significant melt formed in the oxidation tests for Ore B without any addition of fluxes, leading to significant decrease in ore porosity, therefore decreased particle (e.g., magnetite) exposure to oxygen. For these reasons, maximum conversion to hematite is obtained at around $1100^{\circ} \mathrm{C}$ for most of the ores; while for ore $\mathrm{B}$ the maximum oxidation degree is obtained at about $900^{\circ} \mathrm{C}$, approximately $200^{\circ} \mathrm{C}$ lower than ore $\mathrm{C}$ (Fig. 6).

As discussed above, different ores behave differently in oxidation (Fig. 6) since the type and level of gangue have a determining effect on melt formation, and in turn, on interparticle coalescence. Similar to ore $\mathrm{C}, \mathrm{SiO}_{2}$-bearing minerals are common gangue in ores A, D, E2 and F, thus their oxidation behaviour is similar to ore $\mathrm{C}$-oxidation increasing with temperature below $1100^{\circ} \mathrm{C}$. However, oxidation drops dramatically at above $900^{\circ} \mathrm{C}$ for ore $\mathrm{B}$ because of its fine particles which have greater tendency to coalesce and its high levels of alkalis and fluorine which favour melt generation. For ores E1 and E2, which contain the same type of gangue minerals, the difference in oxidation (Fig. 6) would be subject to the difference in gangue level (Table 2), i.e., amount of melt formed at high temperatures. The melt formed was found to be as high as $26 \mathrm{vol} \%$ at $1100^{\circ} \mathrm{C}$ for ore E1. This affects the reaction kinetic conditions and leads to the significant drop in oxidation degree.

Granules similar to those in sinter mix, made from ores $\mathrm{B}$ and $\mathrm{C}$ with small amounts of water were used in the oxidation experiments to increase magnetite exposure to atmosphere. This was aimed to validate the above interpretation regarding the effect of melt formation and particle coalescence on oxidation. After oxidised in flowing air for $60 \mathrm{~s}$, the results for the granules are presented in Fig. 8 to compare with the results for powder samples. It is found that the use of granules considerably improved the oxidation of magnetite for both ores, and the increase is larger for ore B than that for ore $\mathrm{C}$.

Okazaki ${ }^{13)}$ also observed that fusible gangue minerals decreased the oxidation rate of magnetite by melt formation. Thus, high oxidation degree can only be attained by maximising oxidation prior to melt formation.

\subsubsection{Implications of Magnetite Oxidisation to the Sin- tering Process}

Based on the above understanding, it is not expected that complete magnetite oxidation can be achieved in sintering since the process is strongly dependent on exposure of magnetite particle to oxygen, which is limited due to particle coalescence and melt formation, and a less of oxygen to magnetite particles (often magnetite particles are not on the outer layer of granules). In addition, calcination and coke

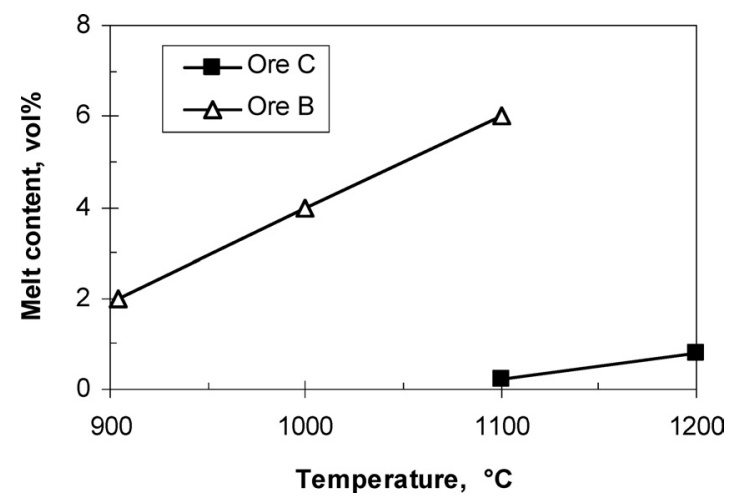

Fig. 7. Melt formation in oxidation of ores $\mathrm{B}$ and $\mathrm{C}$ in flowing air at 1 min residence time.

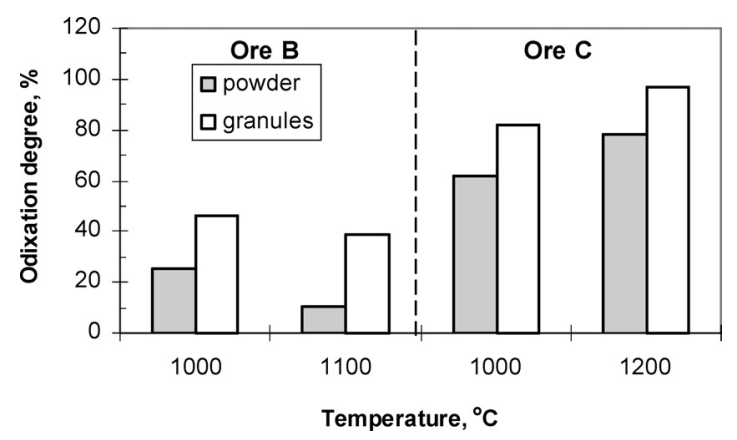

Fig. 8. Effect of sample type (powder and granules) on oxidation for ores B and C.

combustion will lower the oxygen partial pressure in the surrounding gas. Thus, magnetite oxidation is rather limited before the arrival of high temperature zone. A small degree of oxidation may occur ahead the high temperature zone, while magnetite oxidation often takes place during cooling stage of sintering.

Under normal sintering conditions, the thickness of the drying zone may be assumed to be $20-40 \mathrm{~mm}^{14}$ and the vertical sintering speed is considered to be around 20 $\mathrm{mm} / \mathrm{min}$. The residence time of sinter mix in the drying zone is approximately $1-2 \mathrm{~min}$. Measures to promote oxidation may include:

(1) Lower Coke Rate: The overall oxygen partial pressure in the atmosphere in sintering is principally controlled by the coke rate. Lowering coke is an effective measure to promote oxidation;

(2) Improve Granulation: When magnetite concentrate is blended with a coarser ore, the magnetite concentrate likely acts as adhering fines and the coarse ore would form the nuclei of granules during granulation. Magnetite particles would have more opportunity to be exposed to air. Such design seems to be ideal for blends composed of magnetite concentrates and imported coarse hematite, hematite/goethite fines, and

(3) Protect Granules: Moisture tends to rise in the green material zone because of the water condensation. Green material pre-heating with steam is a common technology to prevent granule breakdown in magnetite concentrate sintering. ${ }^{14)}$ Another possibility is to strengthen the granules by adding additives during granulation such as burnt lime. 


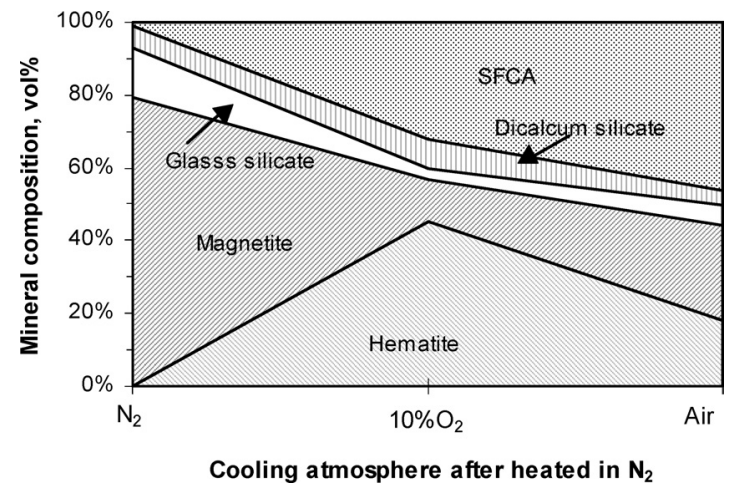

Fig. 9. Sinter mineralogy in magnetite sintering in different atmospheres.

\subsection{Magnetite Sintering Reactions}

Sintering properties of the magnetite concentrates were examined using the rapid heating furnace. Sinter mix with $\mathrm{CaO} / \mathrm{SiO}_{2}=1.8$, made from Magnetite $\mathrm{C}$ and limestone, was sintered under the simulated sintering temperature profile with maximum temperature $1300^{\circ} \mathrm{C}$. The sinter mix was heated to $1300^{\circ} \mathrm{C}$ in $\mathrm{N}_{2}\left(p_{\mathrm{O}_{2}}=10^{-3} \mathrm{~atm}\right)$ and then cooled in either $\mathrm{N}_{2}$, or $10 \% \mathrm{O}_{2}$ or air. The samples were examined with mineralogy and the results are presented in Fig. 9. Silicates are the main bonding phase when magnetite is sintered in atmosphere with low $\mathrm{O}_{2}$ pressure, while SFCA (silico-ferrite of calcium and aluminium) content increases significantly with increasing $\mathrm{O}_{2}$ pressure in atmosphere. Previous work showed that SFCA was not formed from magnetite in pure $\mathrm{CO}_{2}$ at $1244^{\circ} \mathrm{C}$, but formed at the higher oxygen potential $5 \times 10^{-3} \mathrm{~atm}$, i.e., high oxygen potential was favourable to SFCA formation. ${ }^{15)}$ It was proposed that under a high oxygen potential, magnetite oxidised to hematite and subsequently SFCA formed from the hematite and flux. ${ }^{15)}$ Precipitation of SFCA during cooling stage in sintering is an important and, perhaps, is the only way to form SFCA in magnetite sintering.

When magnetite is oxidised to hematite, the sintering system is converted partially to $\mathrm{Fe}_{2} \mathrm{O}_{3}-\mathrm{CaO}-\mathrm{SiO}_{2}-\mathrm{Al}_{2} \mathrm{O}_{3}$ from $\mathrm{Fe}_{3} \mathrm{O}_{4}-\mathrm{CaO}-\mathrm{SiO}_{2}-\mathrm{Al}_{2} \mathrm{O}_{3}$, thus more calcium ferrite forms during sintering. If the amount of new phases (SFCA, dicalcium silicate and glass) formed in sintering represents reactivity of iron ore, magnetite is found to be less reactive than hematite, meaning that hematite is more readily to participate in sintering reactions to generate melt. Higher sintering temperature is then required for magnetite to generate melt of the same quantity compared to hematite, if oxidation of magnetite ore is limited.

\section{Interactions of Chinese Magnetite Concentrates with Hematite and Hematite/Goethite Ores}

\subsection{Assimilation}

It is important to understand the interactions between the imported hematite, goethite and hematite/goethite ores and Chinese magnetite concentrates in sintering since Chinese ore blends are typically made from these ores.

Assimilation of the sinter fines in such blends is an important interaction phenomenon. Sinter mix is granulated prior to charging onto a sinter machine. During granulation

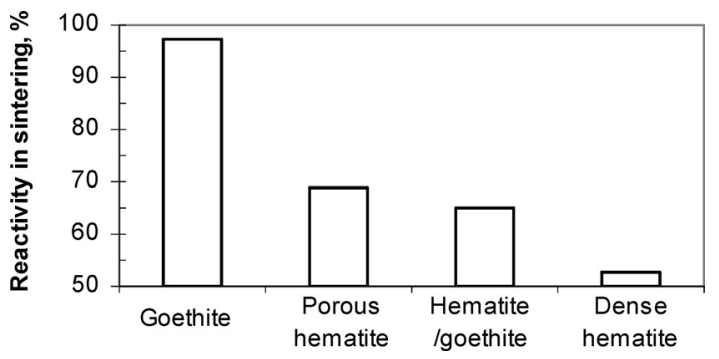

Fig. 10. Assimilation results when adhering fines is made from Magnetite C.

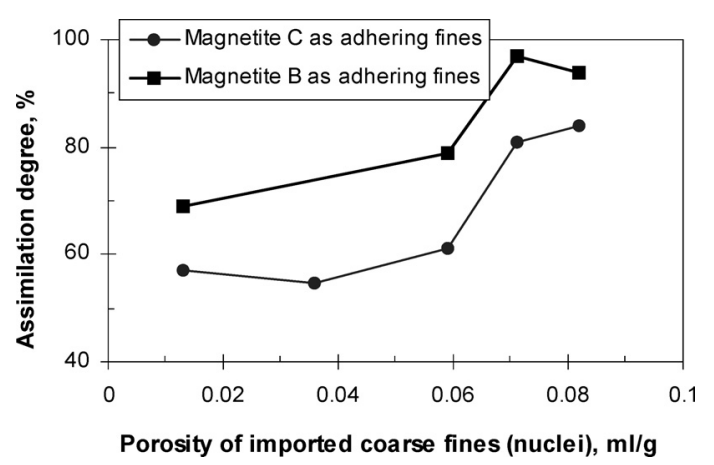

Fig. 11. Assimilation of sinter fines as a function of their porosity.

fine particles adhere onto the surface of large particles because of water lenses to form granules. It is well established that the initial melt is generated from the adhering fines during sintering via reactions between iron ores and fluxes. This melt then assimilates the nucleus particles to produce more melt. Before complete melting is reached, sintering temperature drops. The melt solidifies and mineral phases precipitate out of the melt forming bonding phases that cement the unmelted materials forming lumpy sinter.

Assimilation of a dense hematite ore, a porous hematite ore (Newman ore), a hematite/goethite ore (MAC ${ }^{\mathrm{TM}}$ ore) and a goethite ore (Yandi ore) was investigated with the adhering fines made from magnetite concentrate and limestone. Granules composed of nucleus particles, from iron ore fines, and the adhering fines, were used to represent a number of granules in close proximity to each other and sintered under the simulated sintering temperature profile in the infrared image furnace. Assimilation was measured as the volume percent of relict ore particles after being assimilated by the melt. The assimilation results are presented in Fig. 10 and they show that the porous hematite ore and hematite/goethite ore are relatively easy to be assimilated, meaning that they are more reactive to form melt during sintering. The goethitic ore is particularly reactive. Ores with high assimilation ability is particularly beneficial for melt formation when these ores are blended with less reactive Chinese magnetite concentrates.

Assimilation is a process of interaction between ore particles and the melt present. This interaction involves species transfer and chemical reactions. For such processes to take place, the accessibility of the melt to the surface of the ore particles is critical. At a given size fraction, the accessibility is dependent on properties of the melt, e.g., fluidity and degree of Fe saturation, and the properties of the ore, e.g., porosity. Assimilation degree of different iron ores is plotted as a function of their porosity in Fig. 11. It is observed 
that the degree of assimilation increases with ore porosity. For a given ore, higher assimilation is observed when the adhering fines were made from Ore B. This is because the adhering fines from Ore B generated more melt than Ore C; and the presence of fluorine and high contents of alkalis in Ore B may result in a higher fluidity melt. The melt would more readily penetrate into ore particles, resulting in a higher degree of assimilation. Thus, assimilation of iron ore fines is dependent on properties, particularly the fusion property, of magnetite concentrate in blends.

\subsection{Mineral Formation during Sintering}

Mineral formation during sintering has then been studied since sinter mineralogy determines, to a great extent, sinter quality and provides information regarding the interactions between magnetite concentrate, and hematite and hematite/goethite ores in blends. Analogue sinters with basicity of 1.8 from various ore blends were produced using the infrared furnace. Figure 12 shows that for a porous hematite ore (Newman ore) and Ore C (Table 1) blends sintered in air at the maximum sintering temperature $1270^{\circ} \mathrm{C}$, SFCA increases when the porous hematite ore level increases from 40 to $60 \%$. So the porous hematite ore is beneficial for SFCA formation when it is blended with magnetite concentrates.

There may be two types of melt formed below $1300^{\circ} \mathrm{C}$ in air in the system $\mathrm{CaO}-\mathrm{Fe}_{2} \mathrm{O}_{3}-\mathrm{SiO}_{2}$, i.e., calcium ferric silicate at low local basicity and calcium ferrites at high local basicity. The types of phases precipitated from the melt are strongly dependent on melt composition, atmosphere and cooling rate. At a given composition, the atmosphere and $\mathrm{Fe}^{3+} / \mathrm{Fe}^{2+}$ ratio in the melt would govern what phases form in sinter. The results in Fig. 9 demonstrate a strong dependence of mineral composition on oxygen partial pressure in the atmosphere during sintering, i.e., significant amount of SFCA requires high levels of hematite present. Figure 12 shows that the SFCA content increases with increasing hematite ore in the blends. Hence, blending hematite ore in magnetite-based blend is a very practical way to obtain a considerable amount of SFCA as major bonding phase in sinter when the oxidation of magnetite is not well developed.

Using the same technique as for the results presented in Fig. 12, studies were carried out to compare mineral formation of different ores at given sinter composition $(\mathrm{CaO} /$ $\mathrm{SiO}_{2}=1.8, \mathrm{SiO}_{2}=4.5 \%$ by adjusting chemical reagents). The results (seen in Fig. 13) show that porous hematite (Newman) and hematite/goethite (Marra Mamba ore, e.g., $\mathrm{MAC}^{\mathrm{TM}}$ ) ores have higher ability to form SFCA, which is in line with the assimilation studies that indicate that porous hematite and hematite/goethite ores are easier to react in sintering (Fig. 10).

\section{Granulation and Sintering of Blends Containing Hematite/Goethite Ores and Magnetite Concen- trates}

Granulation is very important as it determines sintering productivity and performance. Granulation is even more important and complex for Chinese ore blends since they often contain very fine magnetite concentrates, and import-

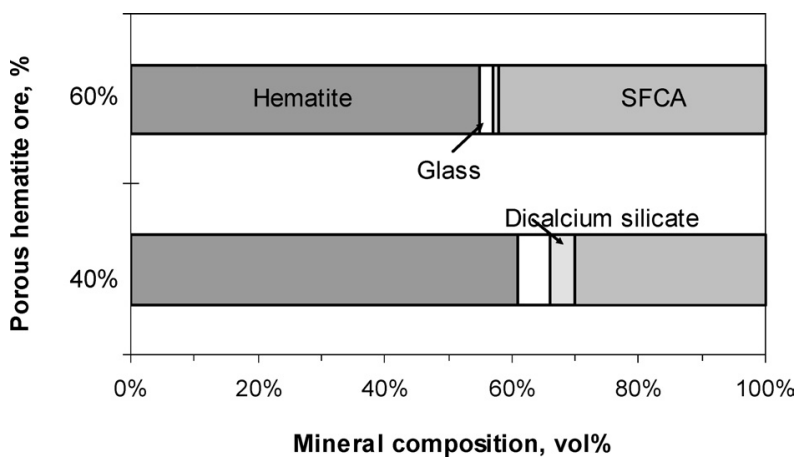

Fig. 12. Mineral composition for "Porous hematite ore-Ore C" blends sintered in air.

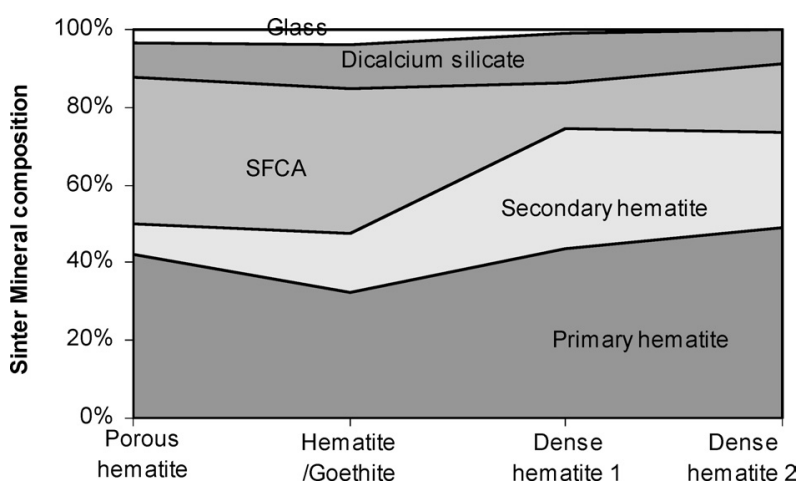

Fig. 13. Mineral composition for sinters of the same composition from different iron ores.

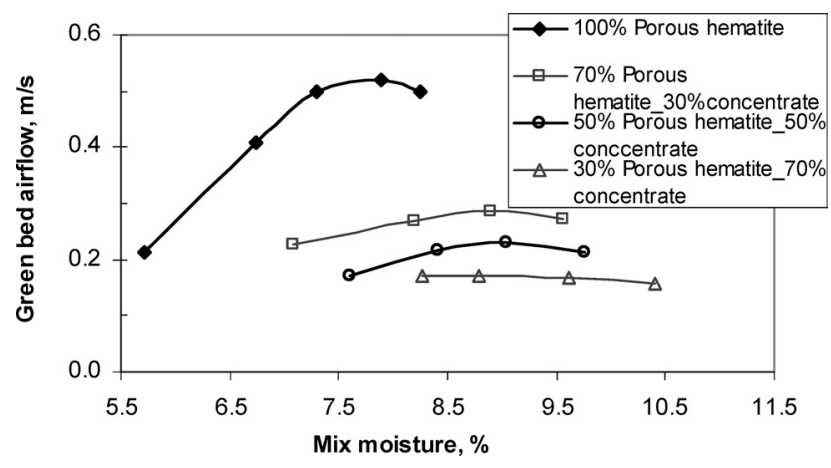

Fig. 14. Porous hematite ore improving granulation when replacing magnetite concentrate.

ed hematite and goethite fines. Issues like lack of nucleus particles, and formation of mini-pellets (non-nucleus granules) become more obvious for blends with high levels of magnetite concentrates.

Granulation studies were carried out for ore blends composed of iron ore, and constant levels of return fines, flux and fuel. Bed permeability was measured by airflow rate through the bed under a given suction of $6 \mathrm{kPa}$. The results for blends containing porous hematite (Newman) ore and a magnetite concentrate are shown in Fig. 14, indicating that the porous hematite ore improves granulation significantly when it replaces magnetite concentrate. The good granulation properties of this porous hematite ore have been observed by end-users in many plants. Figure 14 also indicates that mix moisture in the range tested has small impact on bed permeability for high magnetite concentrate blends probably due to two reasons. One is the high starting mix 


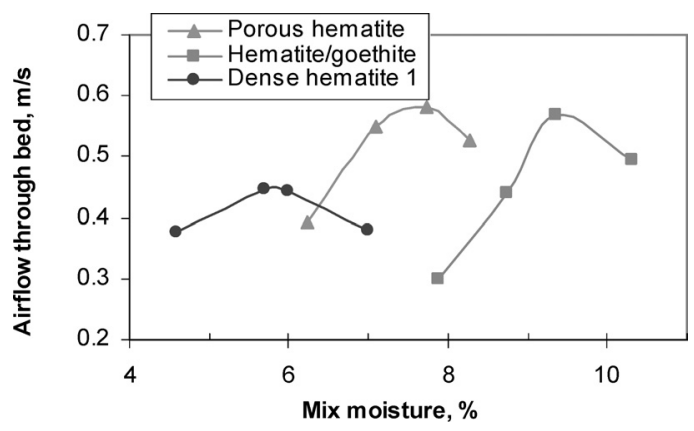

Fig. 15. Granulation properties of different iron ores.

moisture $(7.0 \%)$ in this study-if low mix moisture levels were tested, lower bed permeability would be observed; and another reason is lack of nucleus particles. When magnetite concentrate particles adhere on nucleus particles (the hematite ore in blends) at given moisture level in the range studied, further increase moisture may make granules larger (thicker adhering fines layer), and formation of mini-pellets (no nuclei), which may improve bed permeability; however, these granules would be more compressible, resulting in more compressible bed. Therefore, mix moisture in the range of this work showed small impact on bed permeability.

Figure 15 shows the granulation properties of dense hematite ore, porous hematite and hematite/goethite ore. These experiments were done for single ore with addition of constant levels of return fines, fuel and flux. Bed permeability was measured as airflow cross a bed of $500 \mathrm{~mm}$ height under $6 \mathrm{kPa}$ suction. Clearly the dense ores require less moisture to reach optimal granulation performance, while the hematite/goethite ore $\left(\mathrm{MAC}^{\mathrm{TM}}\right)$ has very good granulation properties provided adequate moisture is added.

Studies have been carried out to examine sintering of blends containing Australian ores and Chinese magnetite concentrates. ${ }^{5,6}$ This work studied blends containing $40-70 \%$ Chinese magnetite concentrate, $40-10 \%$ porous hematite ore and $20 \%$ dense fines $\left(\mathrm{Fe}=66.5 \%, \mathrm{SiO}_{2}=\right.$ $0.94 \%$ ). The magnetite concentrate was replaced by the porous hematite ore to examine the effects of this replacement. The results are presented in Fig. 16. Clearly, replacement of magnetite concentrate with porous hematite ore leads to increases in productivity and sinter strength, and drop in coke consumption, i.e., the porous hematite ore improves sintering performance. In theory, magnetite in sinter blend could reduce energy consumption as its oxidation generates heat. However, magnetite concentrate oxidation is limited in sintering as discussed in this paper. On the contrary, more energy is required for magnetite concentrate sintering since magnetite is less reactive than hematite (Fig. 9) and requires higher coke for melt formation.

When hematite/goethite ore (MAC $\left.{ }^{\mathrm{TM}}\right)$ is used to replace magnetite concentrate in China type ore blends, the similar trend is also observed, i.e., with increasing the hematite/ goethite ore in blend, sinter productivity increases significantly and sinter strength improves slightly while yield and coke rate remain unchanged, as shown in Fig. 17. If productivity was aimed to be unchanged, higher sinter strength would be expected with increasing the hematite/goethite ore. The base blend used contained $40 \%$ porous hematite

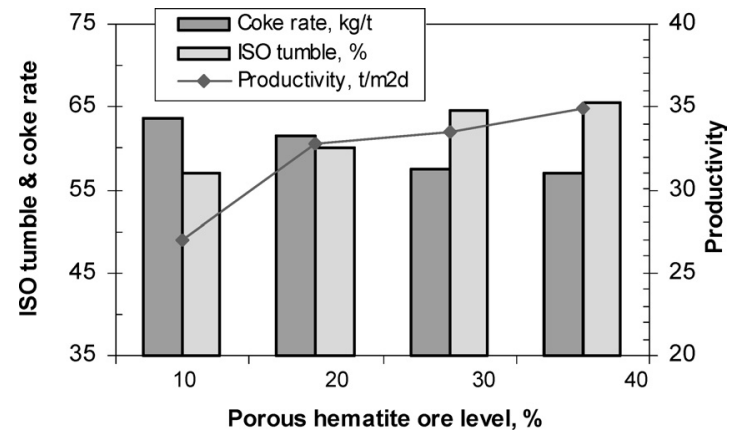

Fig. 16. Porous hematite improving sintering performance when replacing magnetite concentrate.

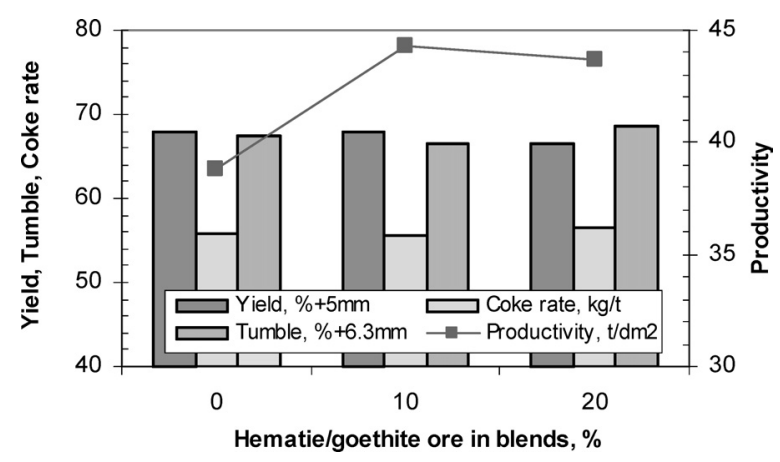

Fig. 17. Hematite/goethite ore improving sintering performance when replacing magnetite concentrate.

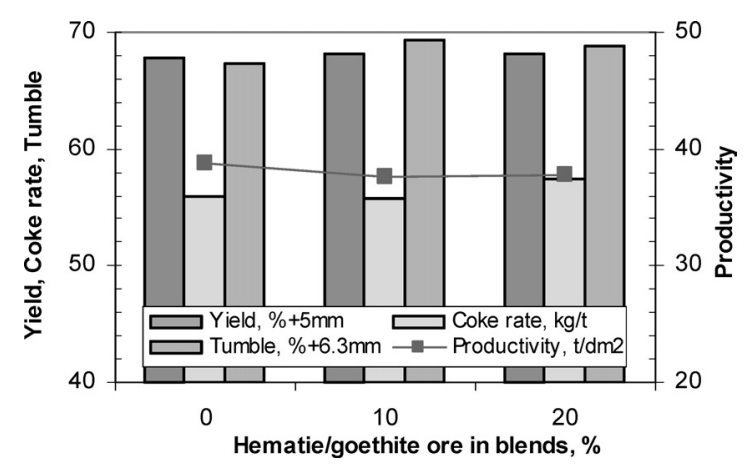

Fig. 18. Sintering performance maintained when hematite/ goethite ore replaces porous hematite ore.

ores, $30 \%$ dense hematite ores and $30 \%$ magnetite concentrate.

Using the same base blend as above, the hematite/ goethite ore was used to replace the porous hematite, the sintering results are presented in Fig. 18. At increased mix moisture, i.e., $6.5 \%$ for the base blend, $6.6 \%$ at $10 \%$ hematite/goethite ore and $6.6 \%$ at $20 \%$ hematite/goethite ore, sintering performance-yield, productivity, coke rate and sinter strength - is maintained almost unchanged. These confirm that the hematite/goethite ore (Marra Mamba) can be blended well in the Chinese ore blends.

\section{Conclusions}

Several Chinese magnetite concentrate were studied and the results show the magnetites are complex in chemistry and mineralogy. Sinter bed strength in wet and dry stage is low for blends containing high levels of magnetite concentrates, thus, the bed loses its original permeability in sinter- 
ing resulting in low productivity. Bed strength increases significantly with increasing imported coarse fines.

Magnetite oxidation is strongly dependent on its exposure to oxygen, oxygen partial pressure, and gangue level and type in sintering. Magnetite oxidation is limited before entering the high temperature zone in sintering due to its limited exposure to oxygen, low oxygen partial pressure, melts formation and particle coalescence. Therefore considerable level of silicates forms in sintering of magnetite alone, and the formation of SFCA occurs primarily in the cooling stage.

Porous hematite and hematite/goethite ores are easy to assimilate compared to dense and magnetite ores. Therefore blending these ores with magnetite ores promotes sintering reactions, particularly SFCA formation. Mixing hematite or hematite/goethite ores with magnetite concentrate improves sinter mix granulation efficiency remarkably. Sintering performance improves significantly when magnetite concentrate is replaced with a porous hematite ore (Newman) or a Marra Mamba ore $\left(\mathrm{MAC}^{\mathrm{TM}}\right)$. Sintering performance is maintained almost unchanged at optimal mix moisture when up to $20 \%$ Marra Mamba ore replaces hematite ore in Chinese type ore blends.

\section{Acknowledgments}

Author would like to thank BHP Billiton Iron Ore for the financial support to this work. The strong support and encouragement from Mr. M. F. Hutchens (Chief Technologist) of Carbon Steel Materials in BHP Billiton are also greatly acknowledged.

\section{REFERENCES}

1) L. X. Yang and C. E. Loo: ISIJ Int., 37 (1997), 449.

2) L. X. Yang and E. Matthews: ISIJ Int., 37 (1997), 854.

3) L. X. Yang and E. Matthews: ISIJ Int., 37 (1997), 1057.

4) L. X. Yang and L. Davis: ISIJ Int., 39 (1999), 239.

5) L. X. Yang and D. Witchard: ISIJ Int., 38 (1998), 1069.

6) L. X. Yang, D. Witchard and Z. N. Yu: ISIJ Int., 40 (2000), 647.

7) L. X. Yang, R. Dukino and M. Hutchens: Iron and Steel Conf., The Chinese Society for Metals, Beijing, (2003), 57.

8) L. X. Yang and L. Jelenich: Ironmaking Conf., The Chinese Society for Metals, Beijing, (2003), 101.

9) L. X. Yang and L. Jelenich: Proc. 61st Ironmaking Conf., ISS, Warrendale, PA, (2002), 307.

10) P. R. Dawson, J. Ostwald and K. M. Hayes: Trans. Inst. Min. Metall. C, 94 (1985), C71.

11) C. E. Loo, R. Dukino and D. Witchard: Trans. Inst. Min. Metall. C, 111 (2002), C33.

12) S. Ergun: Chem. Eng. Prog., 48 (1952), 89.

13) J. Okazaki, Y. Hida and M. Sasaki: Trans. Iron Steel Inst. Jpn., 26 (1986), B236.

14) Q. D. Zhou and L. T. Kong: Theory and Process of Iron Ore Agglomeration, Metallurgical Industry Publisher, China, (1992), 89.

15) L. H. Hsieh and J. A. Whiteman: ISIJ Int., 29 (1989), 625. 